Article

\title{
A Simple and Low-Cost Strategy to Improve Conidial Yield and Stress Resistance of Trichoderma guizhouense through Optimizing Illumination Conditions
}

\author{
Yifan Li ${ }^{1,+}$, Xiya Meng ${ }^{1,+}$, Degang Guo ${ }^{1}$, Jia Gao ${ }^{2} \mathbb{D}$, Qiwei Huang ${ }^{1}$, Jian Zhang ${ }^{1}$, Reinhard Fischer ${ }^{2} \mathbb{D}$, \\ Qirong Shen ${ }^{1}$ and Zhenzhong Yu ${ }^{1, *}$ \\ 1 Laboratory of Bio-Interactions and Crop Health, Jiangsu Provincial Key Lab for Organic Solid Waste \\ Utilization, National Engineering Research Center for Organic-Based Fertilizers, Jiangsu Collaborative \\ Innovation Center for Solid Organic Waste Resource Utilization, Nanjing Agricultural University, \\ Nanjing 210095, China; liyifan@njau.edu.cn (Y.L.); 2020803234@stu.njau.edu.cn (X.M.); \\ 2020103137@njau.edu.cn (D.G.); qwhuang@njau.edu.cn (Q.H.); zhangjian@njau.edu.cn (J.Z.); \\ qirongshen@njau.edu.cn (Q.S.) \\ 2 Department of Microbiology, Institute for Applied Biosciences, Karlsruhe Institute of \\ Technology (KIT)—South Campus, 76131 Karlsruhe, Germany; jia.gao@kit.edu (J.G.); \\ reinhard.fischer@kit.edu (R.F.) \\ * Correspondence: yuzhenzhong@njau.edu.cn \\ $\dagger$ These authors contributed equally to this work.
}

check for updates

Citation: Li, Y.; Meng, X.; Guo, D.; Gao, J.; Huang, Q.; Zhang, J.; Fischer, R.; Shen, Q.; Yu, Z. A Simple and Low-Cost Strategy to Improve Conidial Yield and Stress Resistance of Trichoderma guizhouense through Optimizing Illumination Conditions. J. Fungi 2022, 8, 50. https://doi.org/ $10.3390 /$ jof 8010050

Academic Editor: Baojun Xu

Received: 18 November 2021 Accepted: 29 December 2021

Published: 5 January 2022

Publisher's Note: MDPI stays neutral with regard to jurisdictional claims in published maps and institutional affiliations.

Copyright: (C) 2022 by the authors. Licensee MDPI, Basel, Switzerland. This article is an open access article distributed under the terms and conditions of the Creative Commons Attribution (CC BY) license (https:// creativecommons.org/licenses/by/ $4.0 /)$.

\begin{abstract}
Light is perceived by photoreceptors in fungi and further integrated into the stress-activated MAPK HOG pathway, and thereby potentially activates the expression of genes for stress responses. This indicates that the precise control of light conditions can likely improve the conidial yield and stress resistance to guarantee the low cost and long shelf life of Trichoderma-based biocontrol agents and biofertilizers. In this study, effects of wavelengths and intensities of light on conidial yield and stress tolerance to osmotic, oxidative and $\mathrm{pH}$ stresses in Trichoderma guizhouense were investigated. We found that $2 \mu \mathrm{mol}$ photons $/\left(\mathrm{m}^{2} \times \mathrm{s}\right)$ of blue light increased the conidial yield more than 1000 folds as compared to dark condition and simultaneously enhanced conidial stress resistance. The enhanced conidial stress resistance is probably due to the upregulated stress-related genes in blue light, which is under the control of the blue light receptor BLR1 and the MAP kinase HOG1.
\end{abstract}

Keywords: biofertilizer; light intensity; light wavelength; conidial yield; conidial stress resistance

\section{Introduction}

Fungi adapt continuously to the ever-changing environment to survive in nature. Light, as one of the most common environmental cues, regulates various morphological and physiological processes of fungi [1]. In Aspergillus nidulans, red light stimulates conidiation (asexual development) and represses the formation of cleistothecia (sexual development) [2-4], whereas in Neurospora crassa and Trichoderma atroviride blue light promotes conidiation [5,6]. However, in the plant pathogen Alternaria alternata, blue and green light repress conidiation [7]. Sporangiophores of the zygomycete fungus Phycomyces blakesleeanus exhibit phototropism in response to blue light [8]. White light also accelerates biofilm formation and melanin accumulation in $A$. niger [9]. Hence, light responses vary from fungus to fungus.

Fungi utilize different photoreceptors to perceive a wide range of light wavelengths $[1,6,10,11]$. The most representative fungal photoreceptors studied at the molecular level are the light, oxygen, and voltage (LOV) domain-containing blue-light receptor white collar 1 (WC-1) and vivid (VVD) in N. crassa, and the red-light receptor phytochrome FphA in A. nidulans. The blue- and red-light signaling pathways have been well studied in $N$. crassa and $A$. nidulans, respectively $[1,5,12]$. In addition, fungi can also sense blue light 
with cryptochrome and green light with the retinal-binding protein opsin [13-17]. On the other hand, although responses of many fungi to monochromatic light, which is perceived by specific photoreceptors, have been studied, the effects of the light intensities of specific wavelength on fungal development have received comparatively little attention.

Trichoderma species are widely used in agriculture as biocontrol agents and biofertilizers because of their outstanding performances in antagonizing plant pathogenic fungi and promoting plant growth $[18,19]$. T. guizhouense, initially isolated from mature compost, defeats plant pathogenic fungi through reactive oxygen species (ROS) and secondary metabolites [20,21]. It can also secrete the swollenin protein to benefit plant growth [22]. These properties make T. guizhouense-based biocontrol agents and biofertilizers increasingly popular. In the production of these agents and biofertilizers, high conidial yield and stress resistance are the guarantees of cost reduction and shelf-life extension.

In the entomopathogenic fungus Metarhizium robertsii, light modulates the expression of stress-related genes differentially and therefore affects conidial tolerance [23]. We also proved previously that in A. alternata white light regulates the expression of catalaseencoding genes [7]. Recently, we provided evidence that the blue light receptor BLR1, the white collar 1 orthologue, dominates conidiation in T. guizhouense and the blue light receptor ENV1, the orthologue of VVD, modulates photoadaptation [24]. BLR1 employs the stress-activated MAPK HOG pathway, which is also responsible for the sensing of osmotic, oxidative, and heat-shock stresses in A. nidulans, to activate a large proportion of blue light-regulated genes [24-29]. However, how other monochromatic light affects conidiation in T. guizhouense remains unknown.

Here, we investigated the effects of light wavelengths and intensities on the conidial yield and resistance to several abiotic stresses in T. guizhouense. The mechanism for the enhancement of stress resistance of conidia produced in light was also elucidated.

\section{Materials and Methods}

\subsection{Strains and Culture Conditions}

Wild type of Trichoderma guizhouense NJAU 4742 and three mutants, $\Delta b l r 1, \Delta e n v 1$ and $\Delta h \circ g 1$, which were constructed previously [24], were used in this study. The blue light receptors BLR1 and ENV1 are absent in the $\Delta b l r 1$ - and the $\Delta e n v 1$-mutant strains, respectively. The $\Delta$ hog1-mutant strain lacks the gene encoding MAP kinase HOG1. All strains were cultivated on potato dextrose agar medium (PDA, BD Difco, Germany) at $28^{\circ} \mathrm{C}$. $\mathrm{pH}$, osmotic and oxidative stresses imposed or illumination conditions during the cultivation were indicated additionally in the following experiments.

\subsection{Light System}

The light system used in this study was developed previously [30]. The LED panel hanged in the metal box is $39 \mathrm{~cm}$ long and $28 \mathrm{~cm}$ wide and emits blue $(450 \mathrm{~nm})$, green $(525 \mathrm{~nm})$, red $(700 \mathrm{~nm})$, far-red $(760 \mathrm{~nm})$ and white light. LEDs soldered on the panel were purchased from Ushio Inc. (Tokyo, Japan). The quality of the LEDs was measured by JAZCOMBO S/N:JAZA0503 with a QP400-1-VIS-NIR and CC-3-UV-S spectrometer unit (Ocean Optics). The wavelengths, intensities and specific timings of light were automatically controlled by the self-made software coded for Photon P1 WIFI module. An ocean optics JAZA0503 spectrometer was used to calibrate the software. The photon flux of each LED type was measured at a distance of $20 \mathrm{~cm}$ and the maximum photon flux was limited to $17 \mu \mathrm{mol}$ photons $/\left(\mathrm{m}^{2} \times \mathrm{s}\right)$. Six light boxes were placed in an incubator in the dark room to make sure that the conditions except for illumination in each box are identical.

\subsection{Quantification of Conidia}

Conidial yield was quantified as previously described by Li et al. [24]. The wild type strain was revived on PDA medium for two days at $28^{\circ} \mathrm{C}$ in the dark and afterwards fresh mycelia were inoculated on PDA medium (Ø $6 \mathrm{~cm}$ petri dish) using a hole puncher. The inoculated plates were incubated in darkness or different light conditions at $28^{\circ} \mathrm{C}$ for four 
days in light boxes. Conidia of each plate were harvested with $20 \mathrm{~mL}$ distilled water and the suspension was filtered with Miracloth (Millipore, Merck KGaA, Darmstadt, Germany) to remove the mycelia. The filtrate was diluted properly, and then conidial concentration was determined using a hemocytometer. Three biological replicates of each culture condition were analyzed, and the assay was repeated three times.

\subsection{Assessment of Conidial Stress Resistance}

Assessment of conidial resistance to abiotic stresses was performed as previously described by Dias et al. with minor modifications [23,31]. Conidia produced in different wavelengths or light intensities were harvested as above and spore suspensions were diluted to a final concentration of $1 \times 10^{3}$ conidia $/ \mathrm{mL}$. $100 \mu \mathrm{L}$ of a spore suspension was spread on PDA medium (Ø $9 \mathrm{~cm}$ petri dish) supplemented with different concentrations of $\mathrm{NaCl}(0,0.2,0.4,0.6,0.8$ and $1.0 \mathrm{M}), \mathrm{KCl}(0,0.2,0.4,0.6,0.8$ and $1.0 \mathrm{M})$ and sorbitol $(0,0.4$, $0.8,1.2$ and $1.6 \mathrm{M})$. Oxidative stress was imposed with different concentrations of hydrogen peroxide $(0,1,2$ and $3 \mathrm{mM})$. To analyze the conidial resistance to different $\mathrm{pH}$, the $\mathrm{pH}$ values of the PDA medium were adjusted to 6.0, 7.0, 8.0, 9.0 and 10.0 before autoclaving. The germination rate was then calculated after $30 \mathrm{~h}$ of incubation at $28{ }^{\circ} \mathrm{C}$ in the dark. Each culture condition has three biological replicates and the experiment was performed in triplicate.

\subsection{RNA Isolation and Quantitative Real-Time PCR (qPCR)}

The wild type, the $\Delta b l r 1-$, the $\Delta e n v 1-$, and the $\Delta h o g 1-$ mutant strains were incubated on the PDA medium ( $\varnothing 6 \mathrm{~cm}$ petri dish) covered with cellophane at $28{ }^{\circ} \mathrm{C}$ in the dark for $24 \mathrm{~h}$. The mycelium was harvested in dim-green light immediately or after 45 min illumination of blue light and frozen immediately in liquid nitrogen. Mycelia were disrupted in a homogenizer (Precellys ${ }^{\circledR}$ Evolution Super Homogenizer, Bertin, France) with glass beads at $5500 \mathrm{rpm}$ for $2 \mathrm{~min}$. Total RNA was extracted using the SteadyPure ${ }^{\circledR}$ Plant RNA Extraction Kit (Accurate Biotechnology (Hunan) Co., Ltd., Shenzhen, China). 1 1 g of total RNA was used for cDNA synthesis with HiScript ${ }^{\circledR}$ II Q RT SuperMix for qPCR (+gDNA wiper) (Vazyme Biotechnology Co., Ltd., Nanjing, China). The cDNA synthesis included 2 min of the removal of gDNA at $42{ }^{\circ} \mathrm{C}$, followed by $15 \mathrm{~min}$ at $50{ }^{\circ} \mathrm{C}$ for the reverse transcription reaction. The cDNA samples were diluted to a final concentration of $100 \mathrm{ng} / \mu \mathrm{L}$ in DEPC water for qPCR.

qPCR was performed with the ChamQ SYBR qPCR Master Mix (Vazyme Biotechnology Co., Ltd., Nanjing, China). Each reaction of $20 \mu \mathrm{L}$ contained $10 \mu \mathrm{L}$ of $2 \times$ ChamQ SYBR qPCR Master Mix, $0.2 \mu \mathrm{M}$ of primers and $100 \mathrm{ng}$ of cDNA. The program started with 3 min of the inactivation of the reverse transcription reaction at $95^{\circ} \mathrm{C}$, followed by 40 cycles of PCR reaction $\left(10 \mathrm{~s}\right.$ at $95^{\circ} \mathrm{C}$ and then $30 \mathrm{~s}$ at $\left.60^{\circ} \mathrm{C}\right)$. After each $\mathrm{PCR}$, melting curve analyses were carried out to assess the dissociation characteristics of double-stranded DNA. The translation elongation factor 1 alpha (tef1) gene (OPB38715) was used to normalize the expression level of each gene. Primers used in this study are listed in Supplementary Table S1. Each expression level is the average of three biological replicates.

\subsection{Transcriptome Analysis}

Transcriptome data of T. guizhouense wild type and the mutants $\Delta b \operatorname{lr} 1, \Delta e n v 1$ and $\Delta$ hog1 in response to blue light are available online in the NCBI database Sequencing Read Archive (SRA) under the accession number PRJNA743899. The genes encoding proteins putatively involved in stress resistance were screened from the differentially expressed genes (DEGs) identified in a previous study [24]. The reliability of the transcriptome data was validated by qPCR. The heatmap was generated in the R environment. 


\subsection{Statistical Analysis}

Data are generally presented as means \pm S.D. (standard deviation) with the biological replicates as indicated in each figure legend. The statistical analysis was carried out using One-way ANOVA analysis in the IBM SPSS Statistics 25 program.

\section{Results}

\subsection{Specific Wavelengths of Light Activate Conidiation of T. guizhouense}

Fungi potentially respond to UV, blue, green, red, far-red, and white light, depending on their specific photoreceptors or if the light condition is stressful for them [1]. Hence, we first analyzed the effects of blue, green, red, far-red, and white light on the development of T. guizhouense using a self-designed light system. We cultured T. guizhouense wild type on PDA medium at $28^{\circ} \mathrm{C}$ in blue $(450 \mathrm{~nm})$, green $(525 \mathrm{~nm})$, red $(700 \mathrm{~nm})$, far-red $(760 \mathrm{~nm})$ and white light and also in darkness. The light intensity was set to $1.7 \mu \mathrm{mol}$ photons $/\left(\mathrm{m}^{2} \times \mathrm{s}\right)$. After four days of cultivation, the colonies grown in white and blue light were covered with green conidiophores, whereas in green light and darkness the colonies stayed white and only few conidiophores were observed (Figure 1A). Red and far-red light also promoted the formation of conidiophores to some extent.
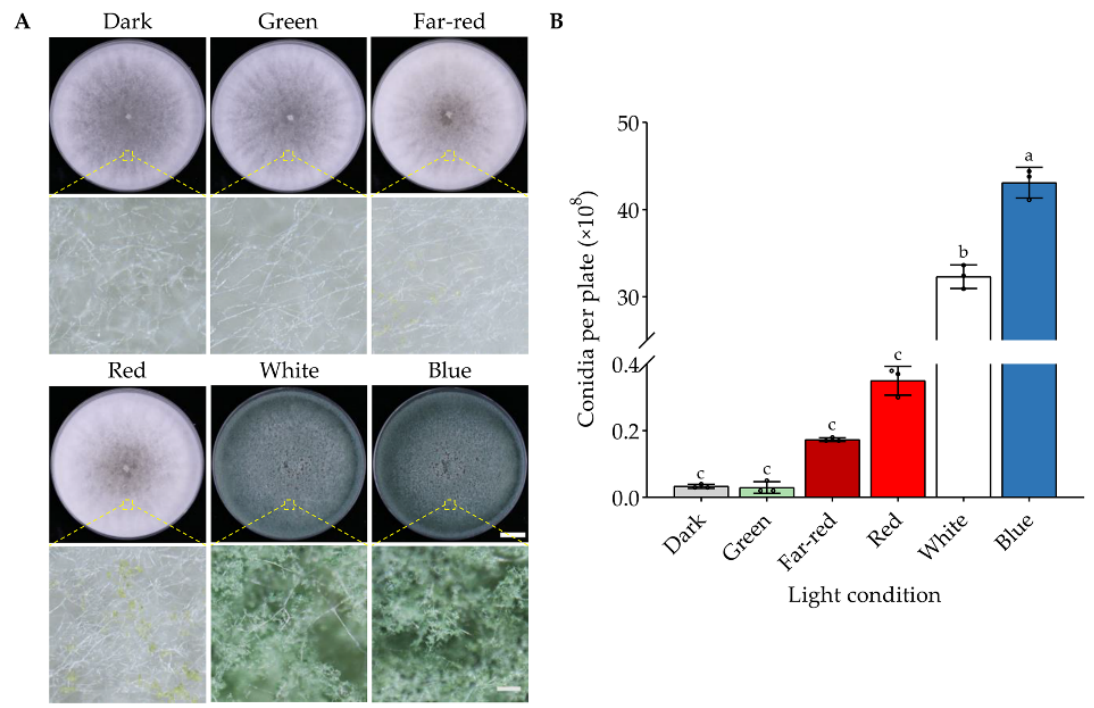

Figure 1. Effects of different wavelengths of light on T. guizhouense conidiation. (A) Phenotype of the wild type strain cultured under different wavelengths of light. The wild type strain was grown on PDA medium at $28{ }^{\circ} \mathrm{C}$ for four days. Scale bar, $1 \mathrm{~cm}$. Colony surface was zoomed in under a stereoscopic micro-scope and the scale bar is $300 \mu \mathrm{m}$. (B) Quantification of conidia produced under different wavelengths of light after four days of cultivation. The mean values for the three biological replicates are displayed. The error bar represents the standard deviation (SD) of three biological replicates. One-way ANOVA was used for the statistical analysis $(p \leq 0.05)$. Means significantly different from each other do not share the same letter.

The conidial yield for each condition was further quantified (Figure 1B). In darkness and green light, the strain produced equal amounts of conidia $\left(0.3 \times 10^{7}\right.$ conidia/plate $)$ suggesting that $T$. guizhouense does not respond to green light as far as the conidiation is concerned. The conidial yield $\left(4.3 \times 10^{9}\right.$ conidia/plate $)$ in blue light was the highest and 1433 folds of that in darkness. Compared with white light $\left(3.2 \times 10^{9}\right.$ conidia/plate), blue light still increased the conidial yield by $34.4 \%$. Conidial yields in red light $\left(3.5 \times 10^{7}\right.$ conidia/plate $)$ and far-red light $\left(1.7 \times 10^{7}\right.$ conidia/plate $)$ were also far lower than that in blue light. 


\subsection{Low Intensity Blue Light Can Promote Conidial Yield Effectively}

Next, we analyzed the effects of blue-light intensities on T. guizhouense conidiation. The intensities of light inside the lightboxes were set to $0,1,2,3,4,5,7,11$ and $15 \mu \mathrm{mol}$ photons $/\left(\mathrm{m}^{2} \times \mathrm{s}\right)$ separately. Wild type was cultured in light boxes for four days and then the conidial yield was quantified. We found that although the conidial yield $\left(4.1 \times 10^{9}\right.$ conidia/plate $)$ in $2 \mu \mathrm{mol}$ photons $/\left(\mathrm{m}^{2} \times \mathrm{s}\right)$ blue light was the highest, the differences between tested intensities were not significant (Figure 2A). Notably, the vegetative growth of the strain was inhibited when the intensity was equal to or more than $4 \mu \mathrm{mol}$ photons $/\left(\mathrm{m}^{2} \times \mathrm{s}\right)$ (Figure $\left.2 \mathrm{~B}\right)$. The diameter of the colony under the light intensity of $4 \mu \mathrm{mol}$ photons $/\left(\mathrm{m}^{2} \times \mathrm{s}\right)$ was inhibited by $4 \%$ in comparison to that in darkness. The diameters of colonies further decreased along with the increase of the light intensities. It is also notable that strong blue light $\left(15 \mu \mathrm{mol}\right.$ photons $\left./\left(\mathrm{m}^{2} \times \mathrm{s}\right)\right)$ activated the conidiation process earlier than the low-intensity blue light $\left(2 \mu \mathrm{mol}\right.$ photons $\left./\left(\mathrm{m}^{2} \times \mathrm{s}\right)\right)$ (Figure $\left.2 \mathrm{C}\right)$. After 2 days of cultivation, the colony grown in strong blue light was smaller but much greener than the ones in darkness and in low-intensity blue light.

A

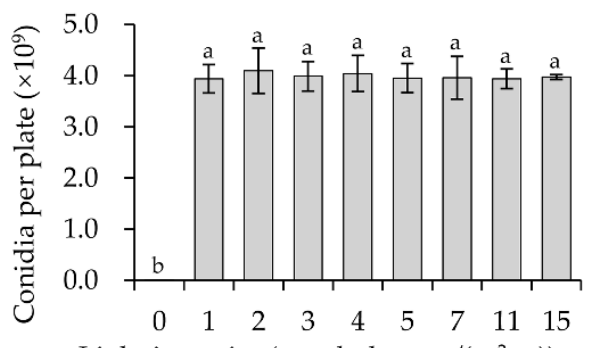

Light intensity $\left(\mu \mathrm{mol}\right.$ photons $\left./\left(\mathrm{m}^{2} \times \mathrm{s}\right)\right)$

B

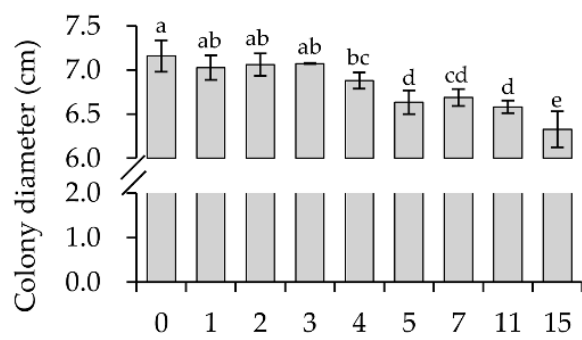

Light intensity $\left(\mu \mathrm{mol}\right.$ photons $\left./\left(\mathrm{m}^{2} \times \mathrm{s}\right)\right)$

C

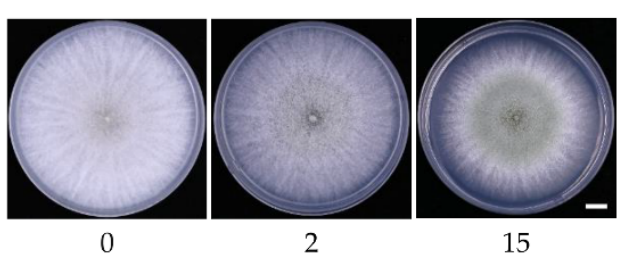

Light intensity $\left(\mu \mathrm{mol}\right.$ photons $\left./\left(\mathrm{m}^{2} \times \mathrm{s}\right)\right)$

Figure 2. Effects of the intensities of blue light on vegetative growth and conidiation. (A) Quantification of the conidia produced in different intensities of blue light. Wild type was grown on the PDA medium at $28{ }^{\circ} \mathrm{C}$ for four days. The error bar represents the SD of three biological replicates. (B) Colony diameter of wild type in different intensities of blue light. The error bar represents the SD of three biological replicates. One-way ANOVA was used for the statistical analysis $(p \leq 0.05)$. Means significantly different from each other do not share the same letter. (C) Phenotype of wild type grown in low and high intensities of blue light. The wild type strain was grown on the PDA medium at $28^{\circ} \mathrm{C}$ for two days. Scale bar, $1 \mathrm{~cm}$. 


\subsection{Blue and White Light Significantly Enhance the Conidial Resistance to Oxidative and $p H$ Stresses}

To analyze the conidial stress resistance, conidia produced in darkness or blue, red, far-red, or white light were harvested, and fresh conidia were directly used for the following experiments. To estimate the oxidative stress resistance, conidia were spread on PDA medium with increasing concentrations (up to $3 \mathrm{mM}$ ) of hydrogen peroxide. The germination rate of the conidia on each plate was calculated after $30 \mathrm{~h}$ of incubation in the dark. At all tested concentrations of hydrogen peroxide, conidia produced under blue or white light were more tolerant to oxidative stress than those produced under other conditions (Figure 3A). After the concentration of $\mathrm{H}_{2} \mathrm{O}_{2}$ was increased to $3 \mathrm{mM}$, the germination rate of conidia formed under blue light $(60.0 \%$ germination rate) was about 1.8 folds of that of conidia generated in the dark (34.2\%), 1.4 folds of that produced under red light $(41.4 \%)$, and 2.9 folds of that under far-red light $(20.6 \%)$.

A

$\mathrm{H}_{2} \mathrm{O}_{2}$
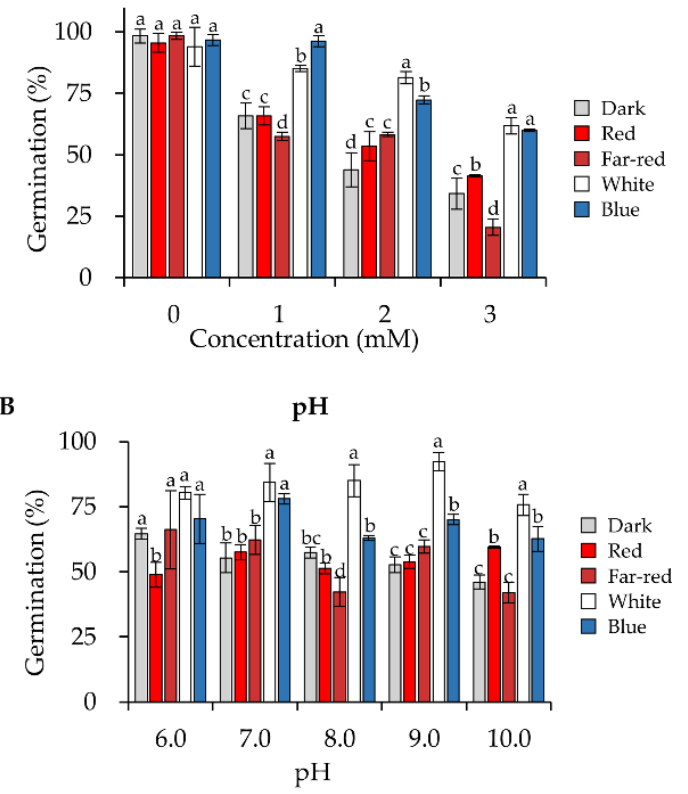

Figure 3. Tolerance to oxidative stress and high $\mathrm{pH}$ of conidia formed under different wavelengths of light. Germination rates of conidia under oxidative (A) or $\mathrm{pH}(\mathbf{B})$ stresses. For all experiments, conidia were spread on the PDA medium with increasing concentrations of $\mathrm{H}_{2} \mathrm{O}_{2}$ or $\mathrm{pH}$ as indicated, and the germination rates were calculated after $30 \mathrm{~h}$ of incubation in the dark. Error bars indicate SD of three biological replicates. One-way ANOVA was used for the statistical analysis $(p \leq 0.05)$. Means significantly different from each other do not share the same letter.

We also assessed the resistance of conidia to different $\mathrm{pH}$, ranging from 6.0 to 10.0 and conidia formed in white and blue light still exhibited increased tolerance to different $\mathrm{pH}$ (Figure 3B). When the $\mathrm{pH}$ was above 7.0, conidia produced under white light were more tolerant than conidia produced under blue light.

\subsection{Blue and White Light Enhance the Conidial Stress Resistance to Several Osmotic Stresses}

To determine the osmotic stress resistance, we first analyzed the germination rates of the conidia produced under different light when incubated on PDA medium supplemented with different concentrations of $\mathrm{NaCl}$. In comparison to darkness, blue and white light significantly enhanced the conidial tolerance towards $\mathrm{NaCl}$ (Figure 4A). When the concentration of $\mathrm{NaCl}$ increased to $1 \mathrm{M}$, the germination rate of conidia formed under blue light $(58.65 \%)$ was 2.5 folds of that in the dark (23.0\%). Conidia formed in red light exhibited similar stress resistance to that in the dark, whereas conidia formed in far-red light were more tolerant than that in red light. We also exposed the conidia to different concentrations 
of $\mathrm{KCl}$ and sorbitol. Likewise, conidia formed in blue and white light were always the most tolerant to these stresses (Figure 4B,C).
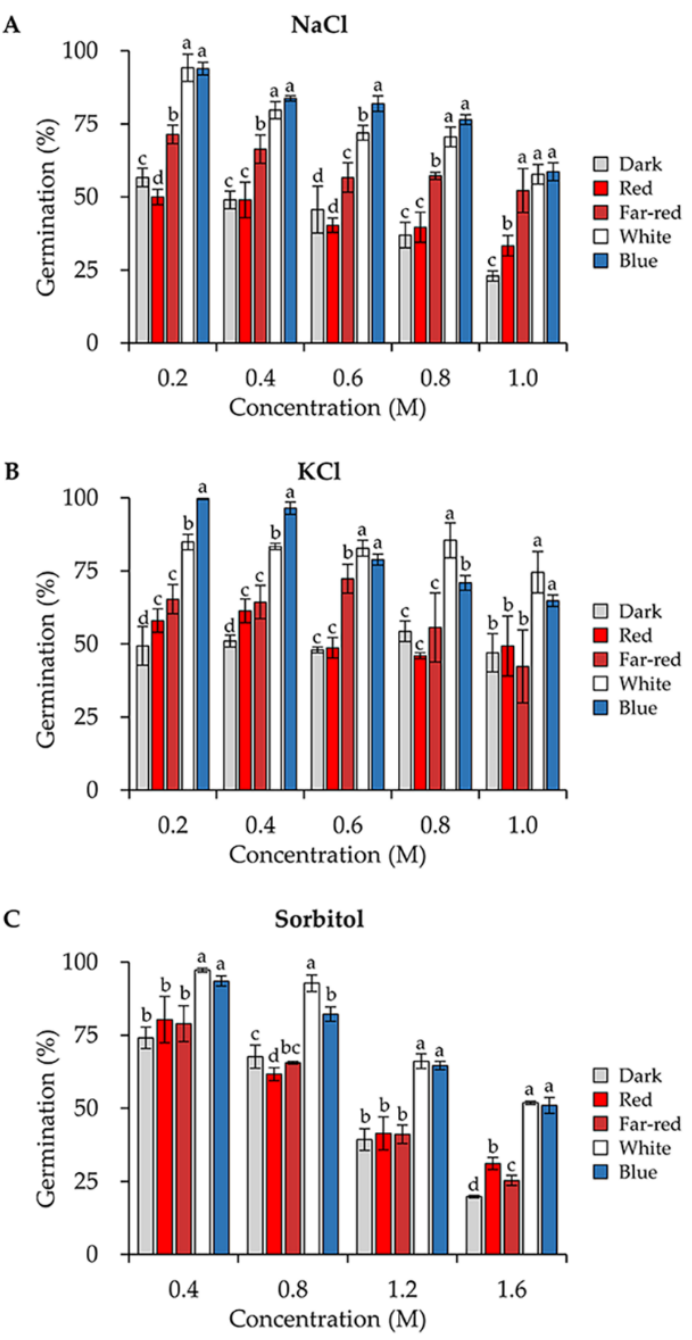

Figure 4. Osmotic stress tolerance of conidia formed under different wavelengths of light. Conidia were spread on the PDA medium with increasing concentrations of $\mathrm{NaCl}(\mathbf{A}), \mathrm{KCl}(\mathbf{B})$ or sorbitol (C) as indicated, and the germination rates were calculated after $30 \mathrm{~h}$ of incubation in the dark. Error bars indicate SD of three biological replicates. One-way ANOVA was used for the statistical analysis $(p \leq 0.05)$. Means significantly different from each other do not share the same letter.

\subsection{Blue Light Upregulates the Expression of the Genes Encoding HOG Pathway Components}

MAPK HOG pathway is crucial for blue light signaling in T. guizhouense [24]. By reanalyzing the transcriptome published previously [24], we found that transcript abundance of ssk2 (OPB39222), pbs2 (OPB41576) and hog1 (OPB38173) encoding components of HOG pathway were all upregulated after growth under blue light (Figure 5A). Moreover, the transcript abundance of ssk1 (OPB38780) encoding an orthologue of $A$. nidulans SskA, the response regulator of the two-component system, was also significantly upregulated. This means in blue light the signaling pathway is probably more sensitive to environmental stresses. 
A

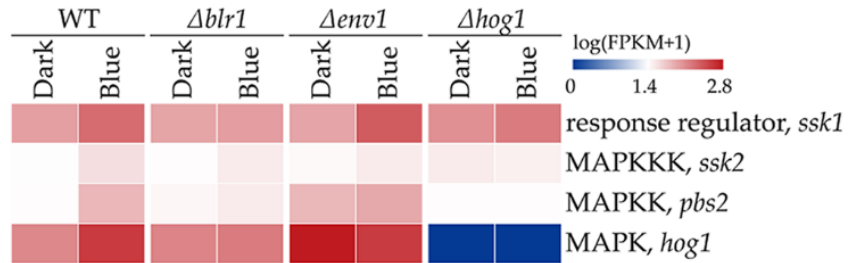

B
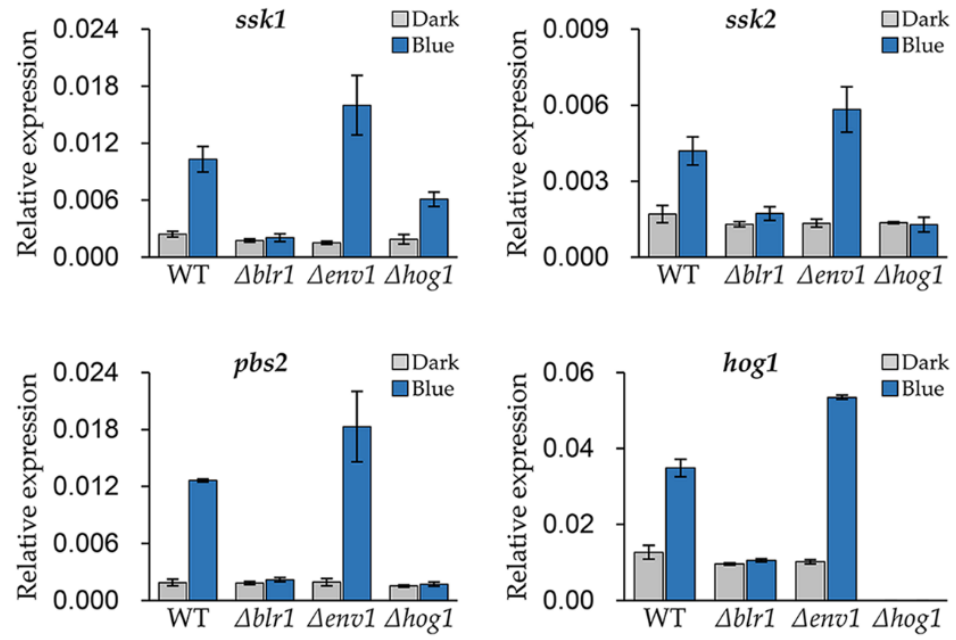

Figure 5. Analysis of transcript abundances of the HOG pathway genes in different strains. (A) Transcriptional abundances of the HOG pathway genes derived from the transcriptome data. (B) Expression levels of the HOG pathway genes in wild type, the $\Delta b l r 1-$, the $\Delta e n v 1$ - and the $\Delta$ hog1-mutant strains under blue light. The expression level of each gene was normalized to the tef1 gene. Error bars indicate $\mathrm{SD}$ of three biological replicates.

To validate the reliability of the transcriptome data and further analyze the regulatory pattern of the photoreceptors on these genes, we measured the expression levels of these genes in wild type, the $\Delta b l r 1-$, the $\Delta e n v 1-$ and the $\Delta h o g 1-m u t a n t$ strains by real-time quantitative PCR (qPCR). In wild type, the expression levels of ssk1, ssk2,pbs2 and pbs2 in blue light were 4.3, 2.5, 6.7 and 2.8 folds of that in the dark respectively (Figure 5B). And the fold changes of ssk1, ssk2, pbs2 and pbs2 in the $\Delta e n v 1$-mutant strain were 10.6, 4.4, 9.6 and 5.2 , respectively, which were higher than that in wild type. However, these genes could not be induced anymore in the $\Delta b l r 1$-mutant strain. In the $\Delta$ hog1-mutant strain, the expression levels of ssk2, pbs2 and hog1 did not change in blue light. Although ssk1 was upregulated 3.2 folds after blue light exposure, the expression level was lower than that in wild type.

\subsection{Blue Light Receptors Regulate the Stress Responsive Genes of T. guizhouense}

Superoxide dismutase (SOD) and catalase (CAT) are crucial for fungi to scavenge reactive oxygen species (ROS) [32]. In our previous study, 1615 blue light responsive genes in T. guizhouense wild type strain were identified through genome-wide gene expression analysis [24]. By reanalyzing the transcriptome data, we screened three CAT1-encoding genes, cat1-1 (OPB39159), cat1-2 (OPB42210) and cat1-3 (OPB40299) and one SOD2-encoding gene, sod2 (OPB46299) in wild type, which were upregulated significantly in blue light (Figure 6A). This result was confirmed again with qPCR in wild type, the $\Delta b l r 1-$, the $\Delta e n v 1-$, and the $\Delta$ hog1-mutant strains. Surprisingly, in wild type the expression level of cat1-1 in response to blue light was increased by 690 folds compared to darkness and in the $\Delta e n v 1-m u t a n t$ strain the expression level was even higher. Likewise, in blue light the expression levels of other CAT- and SOD-encoding genes were upregulated significantly in wild type and the $\Delta e n v 1-$ mutant strain, but the increase was not observed in the $\Delta b l r 1$ and the $\Delta$ hog1-mutant strains. Therefore, the upregulation of the expression of CAT- and SOD-encoding genes are controlled by blue light through BLR1 and HOG1. 

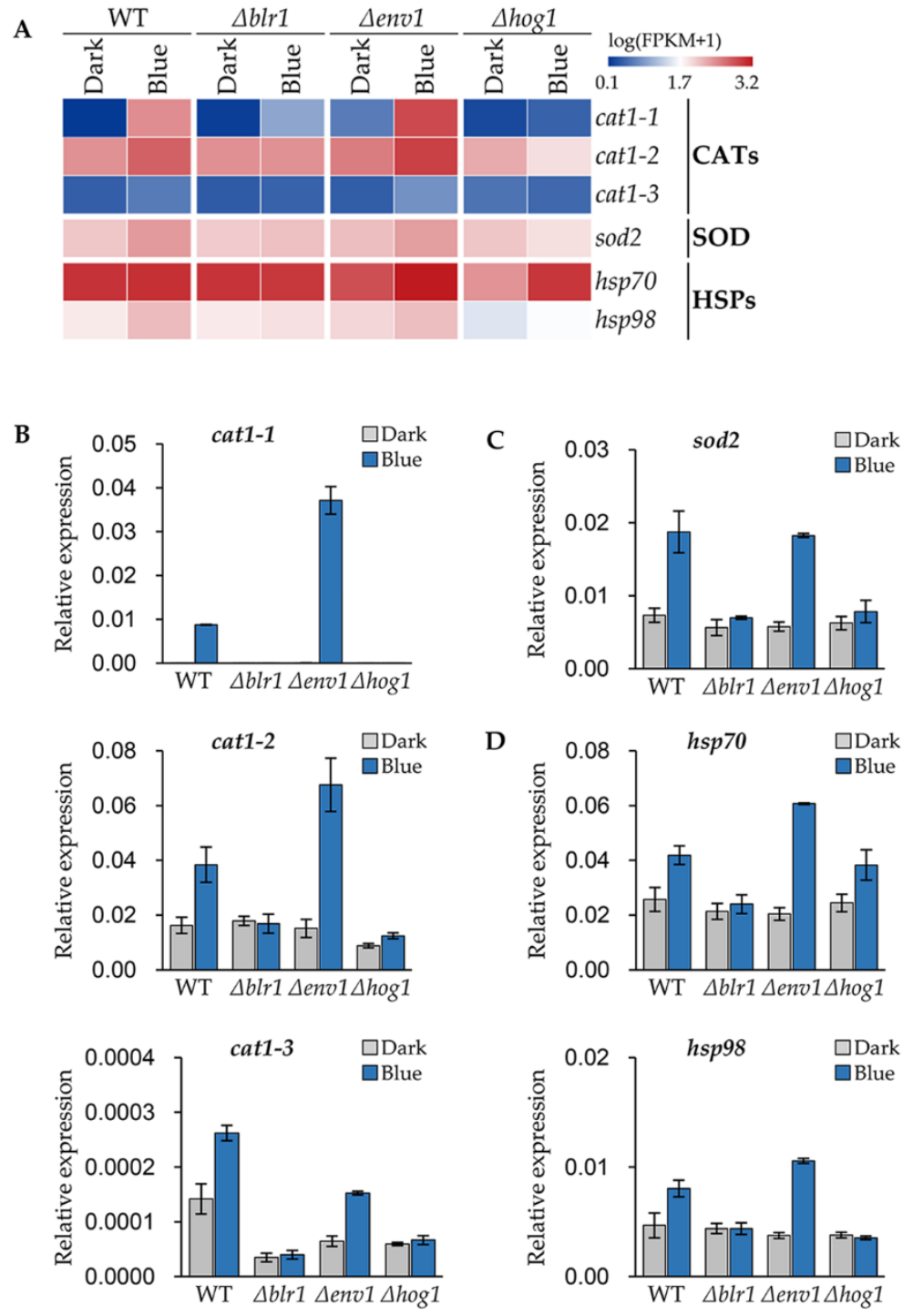

Figure 6. Blue-light-regulated stress response genes identified in T. guizhouense. (A) Transcriptional abundance of the catalase (CAT)-, SOD- and HSP-encoding genes. (B-D) Expression levels of the catalase- (B), SOD- (C) and HSP- (D) encoding genes in wild type, and the $\Delta b l r 1-$, the $\Delta e n v 1$ - and the $\Delta$ hog1-mutant strains. All strains were cultured on PDA medium at $28{ }^{\circ} \mathrm{C}$ for $24 \mathrm{~h}$ and then kept in the dark or exposed to blue light for $45 \mathrm{~min}$. The expression level of the gene was normalized to the tef1 gene. Error bars indicate SD of three biological replicates.

Heat shock proteins (HSPs), which function in refolding misfolded proteins, can protect the cell from damages caused by a variety of environmental stresses [33]. We identified two upregulated HSP-encoding genes $h s p 70$ (OPB39845) and $h s p 98$ (OPB41524) (Figure 6A). After blue light exposure, the expression levels of $h s p 70$ and $h s p 98$ increased $63 \%$ and $72 \%$ respectively in wild type, while in the $\Delta e n v 1$-mutant strain, the expression levels of $h s p 70$ and $h s p 98$ in blue light were 3.0 and 2.8 folds of that in the dark (Figure 6D). Like the CAT- and SOD-encoding genes, the deletion of BLR1 did not cause the expression upregulation of these genes. In the $\Delta h o g 1$-mutant strain, the expression of $h s p 70$ only increased $57 \%$ in blue light, while $h s p 98$ did not change in response to blue light.

\section{Discussion}

The regulatory role of light on fungal development provided a possibility for us to enhance the conidial yield and stress resistance of T. guizhouense. Here, we show that blue light, superior to red, far-red and green light, can efficiently promote conidiation of 
T. guizhouense. The conidiation-related genes in T. guizhouense, indeed, were drastically induced by blue light [24]. The fact that conidial yield in white light was lower than in blue light also suggests some interference of different wavelengths with the blue-light response [12]. Furthermore, red and far-red light slightly promoted the conidiation, which implies that phytochrome is probably functional in T. guizhouense. The biological function of Trichoderma phytochrome is worthy of further study.

Notably, strong blue light activated the early conidiation, but inhibited the growth of vegetative hyphae of $T$. guizhouense. In A. nidulans, strong blue light induces the generation of Reactive Oxygen Species (ROS) in hyphae [30]. More than a moderate light signal, the high intensity blue light $\left(\geq 4 \mu \mathrm{mol}\right.$ photons $\left./\left(\mathrm{m}^{2} \times \mathrm{s}\right)\right)$ is stressful for vegetative hyphae of T. guizhouense, which forces the shift of development from vegetative growth to asexual reproduction. However, low intensities $\left(<4 \mu \mathrm{mol}\right.$ photons $\left./\left(\mathrm{m}^{2} \times \mathrm{s}\right)\right)$ of blue light not only increase the conidial yield of T. guizhouense, but these intensities do not retard the vegetative growth. During the production of conidia in the factory, in order to lower the cost and meanwhile reutilize agricultural wastes, the media for solid fermentation are commonly the discarded crop straws or other plant-derived wastes, which normally contain cellulose as main carbon source [34]. Therefore, it is important not to reduce vegetative growth to get the maximal biomass as a prerequisite for efficient cellulose degradation. Low-intensity blue light also consumes less power. Hence, low-intensity blue light stimulates conidiation, does not affect vegetative growth and is more economic. Low intensity blue light is more practical for large-scale solid fermentation.

Fungi utilize two-component system and the MAPK HOG pathway for sensing and responding to environmental signals [24-29]. The former comprises the hybrid histidine kinases (HHKs), which are potential sensors for different environmental signals, a phosphotransferase and several response regulators (RRs); the latter consists of a MAP kinase kinase kinase (MAPKKK), a MAP kinase kinase (MAPKK) and a MAP kinase (MAPK). The corresponding orthologues of the HOG pathway components in T. guizhouense are the MAPKKK SSK2, the MAPKK PBS2, and the MAPK HOG1. The results here reveal that in blue light, the genes encoding the components of HOG pathway were all upregulated, suggesting that the amounts of these components in conidia are probably increased, which then strengthens the HOG pathway. Hence, the conidia can also respond to other environmental signals more efficiently. The conidia formed in blue and white light were more resistant to osmotic, oxidative and $\mathrm{pH}$ stresses than those formed in other light conditions. Similar effects of light on conidial resistance were also observed in $M$. robertsii [23]. Our results demonstrate that light can significantly upregulate the expression of the stress-related genes, which depends on the light receptor BLR1 and the MAPK HOG pathway. Fungal hydrophobins (HFBs), the small, cysteine-rich, secreted proteins, are involved in conidial stress resistance [35]. Our recent study proved that in T. guizhouense, the production of hydrophobin HFB10 can be induced by blue light through BLR1 and HOG pathway. Moreover, the upregulation of cryptochrome and photolyase family proteins, severing as repair enzymes for UV-induced DNA lesions, are also under the control of BLR1 [24,36].

The blue light receptor BLR1 is essential for conidiation of T. guizhouense in blue light and controls $80 \%$ of light-regulated genes [24]. Although HOG1 controls more than $60 \%$ of light-regulated genes, the genes related to conidiation such as brl1, aba 1 and wet 1 are independent of it. It seems that during the process of conidiation, the role of HOG pathway is to specially modulate conidial fitness according to the intracellular and extracellular signals by equipping the conidia with stress-related proteins. Likewise, in A. nidulans, the viability of conidia was decreased when the MAP kinase SakA/HogA was absent [27]. HOG pathway is a hub of various environmental signals, but how it distinguishes these signals such as osmotic and oxidative stresses, light and heat shock, remains enigmatic. However, it is reasonable that a set of stress-related genes can be awoken not only by one environmental signal but others plugging into HOG pathway. That is why conidia produced in blue light are more resistant to different abiotic stresses. Recently, Rangel et al. showed that in the entomopathogenic fungi Lecanicillium aphanocladii and Simplicillium 
lanosoniveum, the effect of the nutritional stress on conidial resistance is stronger than that of illumination [31]. Conidia formed under nutritional stress are more resistant to several abiotic stresses than those formed in light. Whether the signal of nutritional stress is integrated into HOG pathway or there is an alternative to trigger the expression of stressrelated genes remains to be elucidated in the future. The stronger effect of nutritional stress on conidial resistance also arises the question if one of the signals is overwhelming when light and other stresses coexist. Therefore, a larger regulatory network for gene expression depicting the crosstalk between light and stress signaling needs to be deciphered.

\section{Conclusions}

The strategy to improve the conidial yield and stress resistance of T. guizhouense through optimizing light conditions is feasible. In comparison to darkness, the conidial yield was increased by more than 1400 folds under $450 \mathrm{~nm}$ blue light and the conidial resistance was significantly enhanced. Low-intensity blue light $\left(<4 \mu \mathrm{mol}\right.$ photons $\left./\left(\mathrm{m}^{2} \times \mathrm{s}\right)\right)$ improved the conidial yield and stress resistance simultaneously, but strong blue light $\left(\geq 4\right.$ photons $\left./\left(\mathrm{m}^{2} \times \mathrm{s}\right)\right)$ delayed the vegetative growth of $T$. guizhouense. The enhanced conidial stress resistance is probably attributed to the upregulation of stress-related genes, which is controlled by the light receptor BLR1 and the MAPK HOG pathway.

Supplementary Materials: The following supporting information can be downloaded at: https: / / www.mdpi.com/article/10.3390/jof8010050/s1. Table S1: Oligonucleotides used in this study.

Author Contributions: Conceptualization, Y.L., Q.H., Q.S. and Z.Y.; Investigation, Y.L., X.M. and D.G.; Methodology, Y.L. and X.M.; Supervision, Q.H., J.Z., Q.S. and Z.Y.; Writing—original draft, Y.L.; Writing-review \& editing, J.G., R.F. and Z.Y. All authors have read and agreed to the published version of the manuscript.

Funding: This work was supported by the National Natural Science Foundation of China (NSFC) (Grant Nos. 32070101 and 32072674), the Natural Science Foundation of Jiangsu Province (Grant No. BK20200542), the Jiangsu Agriculture Science and Technology Innovation fund (JASTIF) (Grant Nos. CX(21)2018 and CX(18)3059) and the Fundamental Research Funds for the Central Universities (Grant No. KYRC2021004).

Data Availability Statement: Not applicable.

Conflicts of Interest: The authors declare no conflict of interest.

\section{References}

1. Yu, Z.Z.; Fischer, R. Light sensing and responses in fungi. Nat. Rev. Microbiol. 2019, 17, 25-36. [CrossRef] [PubMed]

2. Blumenstein, A.; Vienken, K.; Tasler, R.; Purschwitz, J.; Veith, D.; Frankenberg-Dinkel, N.; Fischer, R. The Aspergillus nidulans phytochrome FphA represses sexual development in red light. Curr. Biol. 2005, 15, 1833-1838. [CrossRef]

3. Mooney, J.L.; Yager, L.N. Light is required for conidiation in Aspergillus nidulans. Genes Dev. 1990, 4, 1473-1482. [CrossRef]

4. Purschwitz, J.; Mueller, S.; Kastner, C.; Schoser, M.; Haas, H.; Espeso, E.A.; Atoui, A.; Calvo, A.M.; Fischer, R. Functional and physical interaction of blue- and red-light sensors in Aspergillus nidulans. Curr. Biol. 2008, 18, 255-259. [CrossRef] [PubMed]

5. Dasgupta, A.; Fuller, K.K.; Dunlap, J.C.; Loros, J.J. Seeing the world differently: Variability in the photosensory mechanisms of two model fungi. Environ. Microbiol. 2016, 18, 5-20. [CrossRef]

6. Schmoll, M.; Esquivel-Naranjo, E.U.; Herrera-Estrella, A. Trichoderma in the light of day-Physiology and development. Fungal Genet. Biol. 2010, 47, 909-916. [CrossRef] [PubMed]

7. Igbalajobi, O.; Yu, Z.Z.; Fischer, R. Red- and blue-light sensing in the plant pathogen Alternaria alternata depends on phytochrome and the white-collar protein LreA. Mbio 2019, 10, e00371-19. [CrossRef] [PubMed]

8. Sanz, C.; Rodriguez-Romero, J.; Idnurm, A.; Christie, J.M.; Heitman, J.; Corrochano, L.M.; Eslava, A.P. Phycomyces MADB interacts with MADA to form the primary photoreceptor complex for fungal phototropism. Proc. Natl. Acad. Sci. USA 2009, 106, 7095-7100. [CrossRef] [PubMed]

9. Sun, W.J.; Yu, Y.; Chen, J.; Yu, B.; Chen, T.P.; Ying, H.J.; Zhou, S.M.; Ouyang, P.K.; Liu, D.; Chen, Y. Light signaling regulates Aspergillus niger biofilm formation by affecting melanin and extracellular polysaccharide biosynthesis. Mbio 2021, 12, e03434-20. [CrossRef]

10. Fuller, K.K.; Loros, J.J.; Dunlap, J.C. Fungal photobiology: Visible light as a signal for stress, space and time. Curr. Genet. 2015, 61, 275-288. [CrossRef] [PubMed] 
11. Schumacher, J.; Gorbushina, A.A. Light sensing in plant- and rock-associated black fungi. Fungal Biol. 2020, $124,407-417$. [CrossRef] [PubMed]

12. Corrochano, L.M. Light in the fungal world: From photoreception to gene transcription and beyond. Annu. Rev. Genet. 2019, 53, 149-170. [CrossRef] [PubMed]

13. Bayram, O.; Biesemann, C.; Krappmann, S.; Galland, P.; Braus, G.H. More than a repair enzyme: Aspergillus nidulans photolyaselike CryA is a regulator of sexual development. Mol. Biol. Cell 2008, 19, 3254-3262. [CrossRef]

14. Bieszke, J.A.; Braun, E.L.; Bean, L.E.; Kang, S.C.; Natvig, D.O.; Borkovich, K.A. The nop-1 gene of Neurospora crassa encodes a seven transmembrane helix retinal-binding protein homologous to archaeal rhodopsins. Proc. Natl. Acad. Sci. USA 1999, 96, 8034-8039. [CrossRef] [PubMed]

15. Cohrs, K.C.; Schumacher, J. The two cryptochrome/photolyase family proteins fulfill distinct roles in DNA photorepair and regulation of conidiation in the gray mold fungus Botrytis cinerea. Appl. Environ. Microbiol. 2017, 83, e00812-17. [CrossRef] [PubMed]

16. Garcia-Martinez, J.; Brunk, M.; Avalos, J.; Terpitz, U. The CarO rhodopsin of the fungus Fusarium fujikuroi is a light-driven proton pump that retards spore germination. Sci. Rep. 2015, 5, 7798. [CrossRef] [PubMed]

17. Wang, Z.; Wang, J.R.; Li, N.; Li, J.G.; Trail, F.; Dunlap, J.C.; Townsend, J.P. Light sensing by opsins and fungal ecology: Nop-1 modulates entry into sexual reproduction in response to environmental cues. Mol. Ecol. 2018, 27, 216-232. [CrossRef] [PubMed]

18. Ahmed, H.F.A.; Seleiman, M.F.; Al-Saif, A.M.; Alshiekheid, M.A.; Battaglia, M.L.; Taha, R.S. Biological control of celery powdery mildew disease caused by Erysiphe heraclei DC in vitro and in vivo conditions. Plants 2021, 10, 2342. [CrossRef] [PubMed]

19. Druzhinina, I.S.; Seidl-Seiboth, V.; Herrera-Estrella, A.; Horwitz, B.A.; Kenerley, C.M.; Monte, E.; Mukherjee, P.K.; Zeilinger, S.; Grigoriev, I.V.; Kubicek, C.P. Trichoderma: The genomics of opportunistic success. Nat. Rev. Microbiol. 2011, 9, 749-759. [CrossRef]

20. Pang, G.; Sun, T.T.; Yu, Z.Z.; Yuan, T.; Liu, W.; Zhu, H.; Gao, Q.; Yang, D.Q.; Kubicek, C.P.; Zhang, J.; et al. Azaphilones biosynthesis complements the defence mechanism of Trichoderma guizhouense against oxidative stress. Environ. Microbiol. 2020, 22, 4808-4824. [CrossRef] [PubMed]

21. Zhang, J.; Miao, Y.Z.; Rahimi, M.J.; Zhu, H.; Steindorff, A.; Schiessler, S.; Cai, F.; Pang, G.; Chenthamara, K.; Xu, Y.; et al. Guttation capsules containing hydrogen peroxide: An evolutionarily conserved nadph oxidase gains a role in wars between related fungi. Environ. Microbiol. 2019, 21, 2644-2658. [CrossRef] [PubMed]

22. Meng, X.H.; Miao, Y.Z.; Liu, Q.M.; Ma, L.; Guo, K.; Liu, D.Y.; Ran, W.; Shen, Q.R. TgSWO from Trichoderma guizhouense NJAU4742 promotes growth in cucumber plants by modifying the root morphology and the cell wall architecture. Microb. Cell Fact. 2019, 18, 148. [CrossRef] [PubMed]

23. Dias, L.P.; Pedrini, N.; Braga, G.U.L.; Ferreira, P.C.; Pupin, B.; Araujo, C.A.S.; Corrochano, L.M.; Rangel, D.E.N. Outcome of blue, green, red, and white light on Metarhizium robertsii during mycelial growth on conidial stress tolerance and gene expression Fungal Biol. 2020, 124, 263-272. [CrossRef]

24. Li, Y.F.; Sun, T.T.; Guo, D.G.; Gao, J.; Zhang, J.A.; Cai, F.; Fischer, R.; Shen, Q.R.; Yu, Z.Z. Comprehensive analysis of the regulatory network of blue-light-regulated conidiation and hydrophobin production in Trichoderma guizhouense. Environ. Microbiol. 2021, 23, 6241-6256. [CrossRef]

25. Esquivel-Naranjo, E.U.; Garcia-Esquivel, M.; Medina-Castellanos, E.; Correa-Perez, V.A.; Parra-Arriaga, J.L.; Landeros-Jaime, F.; Cervantes-Chavez, J.A.; Herrera-Estrella, A. A Trichoderma atroviride stress-activated MAPK pathway integrates stress and light signals. Mol. Microbiol. 2016, 100, 860-876. [CrossRef] [PubMed]

26. Furukawa, K.; Hoshi, Y.; Maeda, T.; Nakajima, T.; Abe, K. Aspergillus nidulans HOG pathway is activated only by two-component signalling pathway in response to osmotic stress. Mol. Microbiol. 2005, 56, 1246-1261. [CrossRef]

27. Lara-Rojas, F.; Sanchez, O.; Kawasaki, L.; Aguirre, J. Aspergillus nidulans transcription factor AtfA interacts with the MAPK SakA to regulate general stress responses, development and spore functions. Mol. Microbiol. 2011, 80, 436-454. [CrossRef]

28. Yu, Z.Z.; Armant, O.; Fischer, R. Fungi use the SakA (HogA) pathway for phytochrome-dependent light signalling. Nat. Microbiol. 2016, 1, 16019. [CrossRef]

29. Yu, Z.Z.; Ali, A.; Igbalajobi, O.A.; Streng, C.; Leister, K.; Krauss, N.; Lamparter, T.; Fischer, R. Two hybrid histidine kinases, TcsB and the phytochrome FphA, are involved in temperature sensing Aspergillus nidulans. Mol. Microbiol. 2019, 112, 1814-1830. [CrossRef]

30. Yu, Z.Z.; Streng, C.; Seibeld, R.F.; Igbalajobi, O.A.; Leister, K.; Ingelfinger, J.; Fischer, R. Genome-wide analyses of light-regulated genes in Aspergillus nidulans reveal a complex interplay between different photoreceptors and novel photoreceptor functions. PLoS Genet. 2021, 17, e1009845. [CrossRef]

31. Dias, L.P.; Souza, R.K.F.; Pupin, B.; Rangel, D.E.N. Conidiation under illumination enhances conidial tolerance of insect-pathogenic fungi to environmental stresses. Fungal Biol. 2021, 125, 891-904. [CrossRef] [PubMed]

32. Heller, J.; Tudzynski, P. Reactive oxygen species in phytopathogenic fungi: Signaling, development, and disease. Annu. Rev. Phytopathol. 2011, 49, 369-390. [CrossRef]

33. Rangel, D.E.N. Stress induced cross-protection against environmental challenges on prokaryotic and eukaryotic microbes. World J. Microbiol. Biotechnol. 2011, 27, 1281-1296. [CrossRef]

34. Quiroz, R.D.; Roussos, S.; Hernandez, D.; Rodriguez, R.; Castillo, F.; Aguilar, C.N. Challenges and opportunities of the biopesticides production by solid-state fermentation: Filamentous fungi as a model. Crit. Rev. Biotechnol. 2015, 35, 326-333. [CrossRef] 
35. Cai, F.; Gao, R.W.; Zhao, Z.; Ding, M.Y.; Jiang, S.Q.; Yagtu, C.; Zhu, H.; Zhang, J.; Ebner, T.; Mayrhofer-Reinhartshuber, M.; et al. Evolutionary compromises in fungal fitness: Hydrophobins can hinder the adverse dispersal of conidiospores and challenge their survival. ISME J. 2020, 14, 2610-2624. [CrossRef] [PubMed]

36. Tagua, V.G.; Pausch, M.; Eckel, M.; Gutierrez, G.; Miralles-Duran, A.; Sanz, C.; Eslava, A.P.; Pokorny, R.; Corrochano, L.M.; Batschauer, A. Fungal cryptochrome with DNA repair activity reveals an early stage in cryptochrome evolution. Proc. Natl. Acad. Sci. USA 2015, 112, 15130-15135. [CrossRef] [PubMed] 